\title{
A PROSPECTIVE, RANDOMISED, DOUBLE-BLIND COMPARATIVE CLINICAL STUDY OF 0.5\% BUPIVACAINE AND 0.75\% ROPIVACAINE FOR SCIATIC NERVE BLOCK IN PATIENTS UNDERGOING ELECTIVE BELOW KNEE SURGERIES
}

\author{
Swathi Hegde ${ }^{1}$ Manjunath H. G \\ ${ }_{1}^{1}$ Postgraduate Student, Department of Anaesthesiology, MMCRI, Mysore. \\ ${ }^{2}$ Associate Professor, Department of Anaesthesiology, MMCRI, Mysore.
}

ABSTRACT
BACKGROUND
Sciatic nerve block is a useful technique for unilateral lower limb surgeries. Bupivacaine is the most commonly used long acting
amide local anaesthetic agent for peripheral nerve blockade. Ropivacaine, a newly introduced amide local anaesthetic is similar to
Bupivacaine in structure, less potent than bupivacaine and lacks cardiotoxic potential of Bupivacaine. Hence, this study is taken up
to compare the block characteristics of equipotent doses of Bupivacaine and Ropivacaine.

\section{MATERIALS AND METHODS}

After Institutional Ethical Committee clearance and informed consent, 60 patients of either sex, between 18-60 years, belonging to ASA PS 1 and 2, posted for elective lower limb surgeries were enrolled in the study. The study population was randomly divided by sealed envelope technique into Group B $(n=30)$ and Group R $(n=30)$ who received $20 \mathrm{~mL}$ of $0.5 \%$ Bupivacaine and $0.75 \%$ Ropivacaine for sciatic nerve block respectively by classic approach of Labat. Patients in both the groups received femoral nerve block with 15 $\mathrm{mL}$ of $2 \%$ Lidocaine with Adrenaline. Peripheral nerve stimulator was employed to administer the blocks. Onset of sensory and motor block, duration of analgesia, duration of motor block were the primary objectives studied and quality of block, patient and surgeon satisfaction, adverse events, haemodynamic parameters were studied as secondary objectives.

\section{RESULTS}

There were no statistically significant differences in the primary and secondary objectives studied.

\section{CONCLUSION}

$20 \mathrm{~mL}$ of either $0.5 \%$ Bupivacaine or $0.75 \%$ Ropivacaine produces effective and similar block characteristics. However, due to improved safety profile of Ropivacaine in terms of systemic toxicity, Ropivacaine may offer an advantage over Bupivacaine. We also conclude that sciatic nerve block can be a safe alternative anaesthetic technique of choice for lower limb surgeries, as it would provide excellent post-operative analgesia and haemodynamic stability.

\section{KEYWORDS}

Bupivacaine, Ropivacaine, Sciatic Nerve Block.

HOW TO CITE THIS ARTICLE: Hegde S, Manjunath HG. A prospective, randomised, double-blind comparative clinical study of $0.5 \%$ bupivacaine and $0.75 \%$ ropivacaine for sciatic nerve block in patients undergoing elective below knee surgeries. J. Evolution Med. Dent. Sci. 2016;5(87):6480-6484, DOI: 10.14260/jemds/2016/1465

\section{BACKGROUND}

Anaesthesia has evolved into a specialty subject over decades with lot of improvements in the methods employed and the drugs used to provide anaesthesia with least complications. General anaesthesia was one of the most common methods employed to provide anaesthesia. With the introduction of newer and safer local anaesthetics and distinct advantages, regional anaesthesia in the form of central neuraxial block has taken over as the principle technique for most of the lower limb surgeries. However, over recent years, peripheral nerve blockade is increasingly becoming popular because of the additional advantages like ${ }^{1,2,3}$ reduced incidence of adverse haemodynamic effects (Hypotension, bradycardia), no post

Financial or Other, Competing Interest: None.

Submission 23-09-2016, Peer Review 15-10-2016,

Acceptance 24-10-2016, Published 28-10-2016.

Corresponding Author:

Dr. Swathi Hegde,

D/O Vishwanath Hegde, "Susheela,"

Near C. T. O. Complex, Kagodu Thimmappa Nagar,

Sagar, Shimoga-577401.

E-mail: swathihegde16@gmail.com

DOI: $10.14260 / \mathrm{jemds} / 2016 / 1465$ dural puncture headache, prolonged post-operative analgesia, less incidence of post-operative nausea and vomiting, reduced length of hospital stay.

Sciatic nerve block is a useful technique for unilateral lower limb surgeries, particularly in patients considered unsuitable for central neuraxial block. ${ }^{4}$ Sciatic nerve block when combined with femoral nerve block provides effective anaesthesia of lower limb. It may also be used more readily in the presence of minor degree of coagulopathy or after head injury where central neuraxial block is relatively contraindicated. 4

Long acting Local Anaesthetics (LA) are commonly used for sciatic nerve block, as they provide prolonged postoperative analgesia and Bupivacaine is the most commonly used LA for this purpose. Ropivacaine, a newer long acting amide LA has similar clinical characteristics as that of Bupivacaine and is produced as pure S-enantiomer, hence less potential for cardiotoxicity.5,6 Resuscitation after Ropivacaine toxicity is found to be more successful than Bupivacaine. $7,8,9$ The improved safety profile of Ropivacaine may allow the use of higher concentrations to try and hasten the speed of onset. Ropivacaine is found to be half as potent as Bupivacaine, the potency ratio being $1.5: 1$ between Ropivacaine and 
Bupivacaine respectively. ${ }^{10}$ Hence, in this study we compared equipotent doses of Ropivacaine and Bupivacaine, i.e. $20 \mathrm{~mL}$ of $0.5 \%$ bupivacaine and $20 \mathrm{~mL}$ of $0.75 \%$ for sciatic nerve block.

\section{Objectives}

Our aim is to study and compare the clinical efficacy of $20 \mathrm{~mL}$ of $0.5 \%$ Bupivacaine and $20 \mathrm{~mL}$ of $0.75 \%$ Ropivacaine for sciatic nerve block in elective lower limb surgeries.

Primary objectives included onset of sensory blockade, onset of motor blockade, duration of analgesia and duration of motor blockade. Secondary objectives studied were quality of blockade, haemodynamic parameters, patient satisfaction, surgeon satisfaction and adverse effects.

\section{MATERIALS AND METHODS}

After Institutional Ethical Committee clearance and written informed consent, 60 patients aged 18 to 60 years of either sex, belonging to ASA Physical Status 1 and 2, posted for elective lower limb surgeries were enrolled in the study. Patients with known hypersensitivity or contraindications to the study drugs, infection at the site of block, patients with severe renal, hepatic, respiratory or cardiac diseases, patients with severe coagulopathy, morbidly obese patients, pregnant patients, patients with neurological, psychiatric or neurovascular disorders, patient with alcohol/drug abuse and patients who refused the technique were excluded from the study.

The study population was randomly divided into two groups using shuffled sealed envelope method with 30 patients in each group $(n=30)$.

Group B - Received $20 \mathrm{~mL}$ of Bupivacaine 0.5\%,

Group R - Received $20 \mathrm{~mL}$ of Ropivacaine $0.75 \%$ for sciatic nerve block by posterior approach of Labat using peripheral nerve stimulator (Vygon 7501.31). Both the groups received femoral nerve block with $15 \mathrm{~mL}$ of $2 \%$ Lidocaine with 1:200,000 Adrenaline.

A detailed pre-anaesthetic evaluation of each case was done previous day before surgery. A thorough systemic examination was carried out to detect the presence of any systemic disorder. Routine and special investigations were carried out accordingly. Local examination of block site was done to exclude any sign of sepsis, previous injury or previous deformity. Patients were kept nil orally for solids for 6 hours prior to surgery and Tab. Alprazolam $0.5 \mathrm{mg}$ and Tab. Ranitidine $150 \mathrm{mg}$ were given on the night prior to surgery. The patients were reassured, the procedure of block was explained and a written informed consent was obtained. On arrival of the patient in the operation theatre, Star plus of Larsen and Toubro multipara monitors were applied and base line respiratory rate, pulse rate, non-invasive blood pressure, SPO2 and ECG were recorded. Intravenous line was secured with 18-G Intravenous (IV) catheter and started on ringer's lactate infusion. Premedication with Inj. Midazolam $1 \mathrm{mg}$ was given intravenously 5 minutes to the procedure. Study drugs were prepared by one of the anaesthesiologist not involved in the study. Either of $0.5 \%$ Bupivacaine and $0.75 \%$ Ropivacaine were drawn in two $10 \mathrm{~mL}$ syringes and kept on the portable tray before the procedure. The patients and the observing anaesthesiologists were blinded to study drug.

All patients were positioned in Sims' position with the leg to be operated in non-dependent position. Parts painted and draped. A line was drawn from the posterior superior iliac spine to the midpoint of the greater trochanter. A perpendicular line was drawn bisecting this line, which extended $5 \mathrm{~cm}$ caudally. A second line was drawn from the greater trochanter to the sacral hiatus. The intersection of this line with the perpendicular line indicated the point of needle entry. After infiltrating the skin with $1 \%$ Lidocaine injection, the sciatic nerve was located using $10 \mathrm{~cm}$ insulated needle attached to peripheral nerve stimulator with the initial intensity of current set at $1.5 \mathrm{~mA}$. Needle placement was considered optimal when maximal plantar flexion of foot was obtained at a current of $<0.5 \mathrm{~mA}$, as plantar flexion of foot has got more success rate than dorsiflexion of foot. ${ }^{11}$ After negative aspiration for blood, test solution $(20 \mathrm{~mL}$ of either $0.5 \%$ Bupivacaine or $0.75 \%$ Ropivacaine) was injected. Time of completion of injection was taken as time zero.

Immediately after the block placements, patients were assessed for sensory onset every minute by pin prick method on the dorsal and plantar aspects of the foot and sensation was categorised as, 4

$0=$ Sharp (Normal sensation as of contralateral limb).

$1=$ Dull (Pin prick perceived as pressure).

$2=$ Absent (Complete loss of awareness of pinprick).

Motor block was assessed every minute for the onset by assessing plantar or dorsiflexion at the ankle and was graded as, ${ }^{4}$

$0=$ Normal Power

$1=$ Reduced Power.

2 = Complete Motor Block.

At the end of one hour if patient did not develop sensory and motor anaesthesia, the block was considered inadequate ${ }^{12}$ and patients were given General Anaesthesia. For statistical purposes, such patients were excluded.

As all the procedures were performed under standard thigh tourniquet, femoral nerve block was performed. After complete sensory and motor onset in the sciatic nerve distribution, patients were positioned supine. Under aseptic precautions in supine position, femoral artery was palpated and the insulated needle was attached to peripheral nerve stimulator with the initial intensity of current set at $1 \mathrm{~mA}$. The needle was inserted $2 \mathrm{~cm}$ lateral to artery and $2 \mathrm{~cm}$ below the inguinal ligament. Needle placement was considered optimal when maximal quadriceps contraction or patellar snap was observed at a current of $<0.5 \mathrm{~mA} ; 15 \mathrm{~mL}$ of $2 \%$ Lidocaine with 1:200,000 Adrenaline was injected after negative aspiration for blood. After complete sensory onset, a standard thigh tourniquet was applied in all patients.

Throughout the surgery, haemodynamic parameters were recorded every 10 minutes. Patients were monitored for signs of local anaesthetic toxicity. Any hypersensitivity to drugs and other adverse reactions were noted.

In the post-operative period, resolution of motor blockade and duration of analgesia were recorded.

Patient satisfaction with the anaesthetic technique was recorded by asking the patient to assess the block as: very good, good, medium or poor. 12 In the post-operative period, the pain was assessed by visual analogue score and at a score of 5 patients were given analgesic like Inj. Diclofenac $75 \mathrm{mg}$ and the study concluded at this point. 
Surgeon Satisfaction ${ }^{13}$ was Assessed by Three Point Score

1. Completely satisfied. I want the same anaesthesia for future operations.

2. Partially satisfied. This anaesthesia may be adequate, but needs improvement.

3. Not satisfied. I want a different anaesthesia technique for future procedures.

\section{Definitions}

- Onset of sensory blockade: It is defined as the time from the completion of injection of study drug till the subject does not feel the pin prick on dorsal and plantar aspects of the foot.

- Onset of motor blockade: It is defined as the time from the completion of injection of study drug to first loss of motor power.

- Duration of analgesia: It is defined as the time from the onset of sensory blockade till the time patient first requests for post-operative analgesia.

- Duration of motor blockade: It is defined as the time from the onset of motor blockade till the complete recovery of motor power.

- Quality of block: It was assessed using three point scale as follows, 12

$0=$ Satisfactory (If block alone allowed surgery).

$1=$ Unsatisfactory (Need of analgesic supplementation or General Anaesthesia to complete surgery).

For statistical purpose, patients with unsatisfactory block were excluded from the study.

\section{RESULTS}

The two groups did not vary in terms of demographic data.

The mean time for complete sensory onset in Group B was 22.14 minutes and in Group R 21.74 minutes with no statistically significant difference between the two groups.

The two groups did not differ significantly with respect to mean time for complete motor block with time for complete motor block being 27.67 minutes and 28.88 minutes in Group $\mathrm{B}$ and Group R respectively.

Mean duration of analgesia in Group B was 766.11 minutes and 786.46 minutes in Group R with no statistically significant differences. Mean duration of motor block was 730.89 minutes and 734.07 minutes in Group B and Group R respectively. There were no statistically significant differences between Group B and R.

28 patients (90\%) in Group B and 27 (93.3\%) patients in Group R had satisfactory block and those with unsatisfactory block, i.e. 2 patients in Group B and 3 patients in Group R were excluded from the study. Failure rate in Group B was $6.66 \%$ and $10 \%$ in Group R with no statistically significant difference between the two groups. Quality of block, patient satisfaction and surgeon satisfaction were comparable between the groups without statistically significant difference.

All the patients remained haemodynamically stable throughout the procedure. Results were analysed using SPSS software.

\begin{tabular}{|c|c|c|c|}
\hline Variables & Group B & Group R & P value \\
\hline Age (in years) & $38.46 \pm 13.78$ & $39.08 \pm 11.94$ & 0.50 \\
\hline Sex (M/F) & $23 / 7$ & $23 / 7$ & 1 \\
\hline Weight (kgs) & $61.46 \pm 5.84$ & $58.9 \pm 5.52$ & 0.711 \\
\hline \multicolumn{3}{|c|}{$\begin{array}{r}\text { Table 1. Demographic Characteristics } \\
\text { of Study Population (Mean } \pm \text { SD) }\end{array}$} \\
\hline
\end{tabular}

\begin{tabular}{|c|c|c|c|}
\hline Sensory Blockade & Group B & Group R & $\begin{array}{c}\text { P } \\
\text { value }\end{array}$ \\
\hline $\begin{array}{c}\text { Pinprick Perceived } \\
\text { as Dull }\end{array}$ & $15.32 \pm 6.02$ & $14.41 \pm 5.62$ & 0.559 \\
\hline $\begin{array}{c}\text { Complete Sensory } \\
\text { Onset }\end{array}$ & $22.14 \pm 8.52$ & $21.74 \pm 6.74$ & 0.847 \\
\hline \multicolumn{3}{|c|}{ Table 2. Sensory Block in Minutes (Mean \pm SD) } \\
\hline
\end{tabular}

\begin{tabular}{|c|c|c|c|}
\hline Motor Block & $\begin{array}{c}\text { Group B } \\
\text { Mean } \pm \text { SD }\end{array}$ & $\begin{array}{c}\text { Group R } \\
\text { Mean } \pm \text { SD }\end{array}$ & P value \\
\hline $\begin{array}{c}\text { Paresis } \\
\text { (in minutes) }\end{array}$ & $18.28 \pm 8.515$ & $17.71 \pm 6.63$ & 0.780 \\
\hline $\begin{array}{c}\text { Paralysis } \\
\text { (in minutes) }\end{array}$ & $27.67 \pm 7.26$ & $28.88 \pm 6.69$ & 0.524 \\
\hline \multicolumn{4}{|c|}{ Table 3. Motor Block in Minutes (Mean \pm SD) } \\
\hline
\end{tabular}

\begin{tabular}{|c|c|c|c|}
\hline Duration of & Group R & Group B & P value \\
\cline { 2 - 4 } $\begin{array}{c}\text { Analgesia in } \\
\text { Minutes } \\
\text { (Mean } \pm \text { SD) }\end{array}$ & $766.111 \pm 222.041$ & $786.464 \pm 259.65$ & 0.756 \\
\hline \multicolumn{2}{|c|}{ Table 4. Duration of Analgesia in Minutes (Mean \pm SD) } \\
\hline
\end{tabular}

\begin{tabular}{|c|c|c|c|}
\hline & Group B & Group R & $\begin{array}{c}\text { P } \\
\text { value }\end{array}$ \\
\hline $\begin{array}{c}\text { Duration of } \\
\text { Motor B } \\
\text { lock in } \\
\text { Minutes }\end{array}$ & $730.89 \pm 230.23$ & $734.07 \pm 221.04$ & 0.659 \\
\hline \multicolumn{3}{|c|}{ Table 5. Duration of Motor Block in Minutes (Mean \pm SD) } \\
\hline
\end{tabular}

\section{DISCUSSION}

Lower limb nerve blocks are less popular than upper limb blocks due to widespread acceptance, safety and reliability of central neuraxial block. However, interest in lower limb blocks has been increasing in view of prolonged pain relief and shorter hospital stay, which are the two important goals of modern anaesthetic practice. Studies by Imbelloni et al ${ }^{14}$ concluded that combined femorosciatic block can be as effective as unilateral spinal and a safe alternative to spinal anaesthesia. Suzan Adali et al ${ }^{15}$ concluded that peripheral nerve block can be more advantageous in lower limb orthopaedic surgeries. In our study, we compared the block characteristics of $20 \mathrm{~mL}$ of $0.5 \%$ bupivacaine and $20 \mathrm{~mL}$ of $0.75 \%$ ropivacaine for sciatic nerve block in patients undergoing elective lower limb surgery.

Bupivacaine is the most commonly used long acting amide local anaesthetic agent for peripheral nerve blocks. Due to relatively large volume of local anaesthetic required to block the sciatic nerve, systemic toxicity remains a major concern. Ropivacaine, being produced as pure $\mathrm{S}$ enantiomer is less cardiotoxic than bupivacaine. Resuscitation after ropivacaine toxicity is more successful than bupivacaine. ${ }^{7,8,9}$ Hence, we selected to compare these two drugs in our study.

Ropivacaine being less lipid soluble, is less potent than bupivacaine with a potency ratio of $1.5: 1$ between ropivacaine and bupivacaine. ${ }^{10}$ Due to low lipid solubility, ropivacaine is expected to produce a greater differential motor blockade than bupivacaine. ${ }^{6}$ Hence, we compared equipotent doses of bupivacaine and ropivacaine.

Sensory and motor onset times in our study correlated with studies by Conolly et al, ${ }^{4}$ Beaulieu et al, ${ }^{16}$ Sinari D et al ${ }^{17}$ 
and Cuvillion et al ${ }^{12}$ where they did not observe statistically significant difference between the two drugs in terms of onset times.

Onset times in different studies are variable, but comparable. Relatively large size of sciatic nerve makes the onset time less predictable as the drug has to diffuse through layers of nerve fibre.

Chandini M Soni ${ }^{18}$ and Vaghadia et a ${ }^{19}$ compared similar concentrations of drugs for brachial plexus block and found no significant differences. Onset time of block was shorter due to smaller diameter of brachial plexus.

Duration of analgesia in our study correlated with studies by Conolly $\mathrm{C}^{4}$ and Laura Bertini et al. ${ }^{20}$

Casati et al,21 Vaghadia et al,19 Chandini M Soni 18 and Tripathi $\mathrm{D}$ et al 22 where they found no statistically significant differences between the two drugs.

Duration of motor block in our study was comparable with studies by Conolly et al,12 Fanelli G, ${ }^{23}$ Laura Bertini et al,20 Vaghadia et al, ${ }^{19}$ Misiolek et al, ${ }^{24}$ Tripathi et al ${ }^{22}$ and Chandini M. Soni et $\mathrm{al}^{18}$ and there was no statistically significant difference between two of the study drugs.

The study groups did not differ with respect to secondary objectives of the study. Quality of block, patient and surgeon satisfaction were comparable between the groups. There was no haemodynamic instability throughout the procedure.

\section{CONCLUSION}

Our study shows that $0.75 \%$ Ropivacaine has similar block characteristics as that of $0.5 \%$ Bupivacaine. However, due to large volume of local anaesthetic solution used in peripheral nerve blockade, the potential risk of dangerous inadvertent intravascular injection still exists. Due to safety profile of Ropivacaine over Bupivacaine in terms of cardiovascular and central nervous system toxicity, it can be concluded that $0.75 \%$ Ropivacaine is a preferred safer agent of choice for sciatic nerve blockade than $0.5 \%$ Bupivacaine.

\section{REFERENCES}

1. Murray JM, Derbyshire S, Shields MO. Lower limb blocks. Anaesthesia 2010;65(1):57-66.

2. Jankowski CJ, Horlocker TT, Rock MJ, et al. Femoral 3-in1 nerve block decreases recovery room time and charges and time to hospital discharge after outpatient knee arthroscopy. Reg Anesth Pain Med 1998;23(3):60.

3. Kettner SC, Willschke H, Marhofer P. Does regional anaesthesia really improve outcome? British Journal of Anaesthesia 2011;107(S1):i90-5.

4. Connolly C, Coventry DM, Wildsmith JA. Double blind comparison ropivacaine $7.5 \mathrm{mg} / \mathrm{ml}(-1)$ with bupivacaine $5 \mathrm{mg} / \mathrm{ml}(-1)$ for sciatic nerve block. Br J Anaesth 2001;86(5):674-7.

5. Reiz S, Nath S. Cardio toxicity of local anaesthetic agents. Br J Anaesth 1986;58:736-46.

6. McClure JH. Ropivacaine. Br J Anaesth 1996;76:300-7.

7. Feldman HS, Arthur GR, Pitkanen M, et al. Treatment of acute systemic toxicity after the rapid intravenous injection of ropivacaine and bupivacaine in the conscious dog. Anaesth Analg 1991;73(4):373-84.

8. Groban L, Deal DD, Vernon JC, et al. Cardiac resuscitation after incremental over dosage with lidocaine bupivacaine, levobupivacaine and ropivacaine in anaesthetised dogs. Anaesth Analg 2001;92(1):37-43.
9. Scott DB, Lee A, Fagan D, et al. Acute toxicity of ropivacaine compared with that of bupivacaine. Anaesth Analg 1989;69(5):563-9.

10. Berde BC, Strichartz RG. Local Anaesthetics. Chapter 36. In: Miller's Anaesthesia. $8^{\text {th }}$ ed. Philadelphia: Elsevier Saunders 2015:pp 1049.

11. Taboada M, Atanassoff PG, Rodriguez J, et al. Plantar flexion seems more reliable than dorsiflexion with labat's sciatic nerve block: a prospective randomized comparison. Anesth Analg 2005;100(1):250-4.

12. Cuvillon $P$, Nouvellon E, Ripart J, et al. A comparison of the pharmacodynamics and pharmacokinetics of bupivacaine, ropivacaine (with epinephrine) and their equal volume mixtures with lidocaine used for femoral and sciatic nerve blocks: a double-blind randomized study. Anesth Analg 2009;108(2):641-9.

13. Casati A, Cappelleri G, Aldegheri G, et al. Total intravenous anesthesia, spinal anesthesia or combined sciatic-femoral nerve block for outpatient knee arthroscopy. Minerva Anestesiol 2004;70(6):493-502.

14. Imbelloni LE, deRezende GV, Ganem EM, et al Comparative study between combined sciatic femoral nerve block, via single injection, and spinal block anesthesia for unilateral surgery of lower limb. Rev Bras Anestesiol 2010;60(6):584-92, 324-8.

15. Adali S, Erkalp K, Erden V, et al. Spinal anaesthesia and combined sciatic nerve/lumbar plexus block techniques in lower extremity orthopedic surgery. Acta Orthop Traumatol Turc 2011;45(4):225-32.

16. Beaulieu $\mathrm{P}$, Babin $\mathrm{D}$, Hemmerling $\mathrm{T}$. The pharmacodynamics of ropivacaine and bupivacaine in combined sciatic and femoral nerve blocks for total knee arthroplasty. Anesth Analg 2006;103(3):768-74.

17. Sinardi D, Marino A, Chillemi S, et al. Sciatic nerve block with lateral popliteal approach for hallux valgus correction. Comparison between $0.5 \%$ bupivacaine and $0.75 \%$ ropivacaine. Minerva Anestesiologica 2004;70(9):625-9.

18. Soni MC, Hetal H. Comparison of the motor and sensory block by ropivacaine and bupivacaine in combination with lignocaine in supraclavicular block. Natl J Med Res 2013;3(4):353-7.

19. Vaghadia $H$, Chan $V$, Ganapathy $S$, et al. A multicentre trial of ropivacaine $7.5 \mathrm{mg} / \mathrm{ml} \mathrm{V} / \mathrm{s}$ bupivacaine $5 \mathrm{mg} / \mathrm{ml}$ for supraclavicular brachial plexus anaesthesia. Can J Anaesth 1999;46(10):946-51.

20. Bertini L, Tagariello V, Mancini S, et al. $0.75 \%$ and $0.5 \%$ ropivacaine for axillary brachial plexus block: a clinical comparison with $0.5 \%$ bupivacaine. Regional Anaesthesia and Pain Medicine 1999;24(6):514-8.

21. Casati A, Fanelli G, Aldegheri G, et al. Interscalene brachial plexus anaesthesia with $0.5 \%, 0.75 \%$ or $1 \%$ ropivacaine: a double blind comparison with $2 \%$ mepivacaine. $\mathrm{Br} \mathrm{J}$ Anaesth 1999;83(6):872-5.

22. Tripathi D, Shah K, Shah C, et al. Supraclavicular brachial plexus block for upper limb orthopaedic surgery: a randomized, double blinded comparison between ropivacaine and bupivacaine. The Internet Journal of Anesthesiology 2012;30(4). 
23. Fanelli G, Casati A, Beccaria $P$, et al. Double-blind comparison of ropivacaine, bupivacaine, and mepivacaine during sciatic and femoral nerve blockade. Anesth Analg 1998;87(3):597-600.
24. Misiolek HD, Kucia HJ, Knapic P, et al. Brachial plexus block with ropivacaine and bupivacaine for the formation of AV fistula in patients with end stage renal failure. EJA 2005;22(6):473-5. 